\title{
Trans-Differentiation of Rat Mesenchymal Stem Cells into Dopaminergic Neurons for Cell Transplantation
}

Ryan M Welchko ${ }^{1,2}$, Travis D Hulse ${ }^{1,2}$, Sabrina S Dieffenbach ${ }^{1,2,3}$, Gabrielle P Shall ${ }^{1,2}$, Wanjing Huo $0^{1,2,3}$, Leslie R Siegal ${ }^{1,2,3}$, Jared R Watters ${ }^{1,2}$ Xavier T Leveque ${ }^{1,2}$, Michael I Sandstrom ${ }^{2,3}$ Julien Rossignol ${ }^{1,2,4}$, Ming Lu L $^{1,2,3}$, and Gary L Dunbar ${ }^{1,2,3,5 *}$

${ }^{1}$ Field Neurosciences Institute Laboratory for Restorative Neurology

${ }^{2}$ Program in Neuroscience

${ }^{3}$ Department of Psychology

${ }^{4}$ College of Medicine, Central Michigan University, Mount Pleasant, Michigan, USA

${ }^{5}$ Field Neurosciences Institute., 4677 Towne Centre Rd. Suite 101 Saginaw, Michigan, USA

\begin{abstract}
Objective: Transplantation of human embryonic dopaminergic progenitors within the striata of PD patients has provided encouraging results, but ethical concerns and tissue availability limit this approach. The use of mesenchymal stem cells (MSCs) provides a readily available source of cells, as they are derived from adult tissue. This in vitro study explored the use of MSCs as a cell source for DA neuronal induction utilizing a single adenovirus.

Methods: Our lab developed a novel adenovirus expressing multiple viral $2 \mathrm{~A}$ genes allowing for the polycistronic expression of multiple genes (Ascl1, Lmx1a, and Nurr1) for transcription factors that are involved in DA neuron differentiation and used the gene for green fluorescent protein $(g f p)$ to track transfection. MSCs were cultured with the adenovirus, monitored morphological changes as well as expression of $g f p$ as evidenced by fluorescence microscopy. The presence of the viral DNA within the transfected cells was confirmed with PCR, Immunocytochemistry and RTPCR.

Results: MSCs cultured with the adenovirus, resulted in morphological changes as well as expression of gfp as evidenced by fluorescence microscopy. The presence of the viral DNA within the transfected cells was confirmed with PCR. Immunocytochemistry and RT-PCR analyses revealed that, cells expressing gfp have nuclear co-labeling of translated transcription factors LMX1a, and NURR1, as well as an up-regulation of these genes, along with an up-regulation of downstream gene targets, such as tyrosine hydroxylase (TH), and the dopamine transporter (DAT).
\end{abstract}

Keywords: Mesenchymal stem cells; Stem cell therapy; Mesenchymal stem cell differentiation; Dopaminergic neuron differentiation; Parkinson's disease treatments; Parkinson's disease; Cell transplantation

\section{Introduction}

Parkinson's disease (PD) is the second most common neurodegenerative disease, with approximately $1 \%$ of the population of 65 years and older being afflicted [1]. Primary symptoms, which often appear around 60 years of age, are caused by the death of dopaminergic (DA) neurons within the nigrostriatal pathway [2]. Currently, there is no cure for PD and treatments are only palliative in nature. To date, the most popular treatment is the use of the chemical, levodopamine (L-dopa), which is a precursor to dopamine, and is administered to PD patients to alleviate symptoms. However, the effectiveness of L-dopa diminishes over years of therapy [3]. Therefore, more effective strategies to ameliorate the loss DA are needed.

One potential new strategy for treating PD is cell replacement therapy [4]. The first clinical trials for cell replacement therapy utilized ventral mesencephalon tissue from aborted human embryos and proved to reduce some PD symptoms in open-label trials with about 4 to 8 patients in each trial. Along with reduction in motor deficits, effective duration of L-dopa treatment and a decrease in the reliance on the drug was reported [5-8]. However, double-blind clinical trials in the United States $[9,10]$, did not reveal significant decreases in symptoms between control and treatment groups, and some patients actually developed dyskinesia related to the transplants. Olanow and colleagues [10] reported that $56.5 \%$ of the patients developed these dyskinesias at 6-12 months after transplantation. The cause of dyskinesia, which became known as graft-induced dyskinesia (GID), has been attributed to the lack of specificity in the types of cells transplanted and their improper integration into the host tissue [11].
An alternative to the use of embryonic cells, the use of adult stem cells has been proposed. To this end, mesenchymal stem cells (MSCs), which have been shown to Trans-differentiate into DA neurons, provide a readily accessible source of adult stem cells. Further, MSCs that have been semi-differentiated into dopaminergic neuronal-like progenitors have been proposed as a potentially effective means of augmenting cellular therapy for PD $[12,13]$.

Human MSCs have been shown to differentiate into DA neurons, cultured with recombinant protein morphogens, sonic hedgehog (SHH), fibroblast growth factor 8 (FGF-8), basic fibroblast growth factor (BFGF), and brain derived neuron factor (BDNF) [12]. Additionally, these cells exhibit robust action potentials that are phenotypically similar to true DA neurons [12]. Furthermore, Barzilay and colleagues [13] reported a significant increase in tyrosine hydroxylase expression when the transcription factor (TF) Lmxla was transduced into the MSCs prior to their differentiation, compared to cells that were not

*Corresponding author: Gary L. Dunbar, Field Neurosciences Institute Laboratory for Restorative Neurology, Program in Neuroscience, Department of Psychology, Central Michigan University, Mount Pleasant, Michigan, USA Field Neurosciences Institute, 4677 Towne Centre Rd. Suite 101 Saginaw, Michigan USA, Tel: 9897743001; E-mail: dunba1g@cmich.edu

Received March 16, 2018; Accepted March 30, 2018; Published April 30, 2018

Citation: Welchko RM, Hulse TD, Dieffenbach SS, Shall GP, Wangjing $H$, et al. (2018) Trans-Differentiation of Rat Mesenchymal Stem Cells into Dopaminergic Neurons for Cell Transplantation. J Stem Cell Res Ther 8: 421 doi: $10.4172 / 2157-7633.1000421$

Copyright: (c) 2018 Welchko RM, et al. This is an open-access article distributed under the terms of the Creative Commons Attribution License, which permits unrestricted use, distribution, and reproduction in any medium, provided the original author and source are credited. 
Citation: Welchko RM, Hulse TD, Dieffenbach SS, Shall GP, Wangjing H, et al. (2018) Trans-Differentiation of Rat Mesenchymal Stem Cells into Dopaminergic Neurons for Cell Transplantation. J Stem Cell Res Ther 8: 421. doi: 10.4172/2157-7633.1000421

Page 2 of 7

transduced [13]. These cells also displayed significant increases in other DA TFs. Therefore, transduction methods utilizing TF genes and morphogens, such as SHH, can be utilized to transdifferentiate MSCs.

This in vitro study explored the use of MSCs as a cell source induction of DA neurons. To this end, our lab developed a novel method of utilizing an adenovirus for the polycistronic expression of multiple TF genes with the viral gene $2 \mathrm{~A}$ placed between each TF gene (Ascl1, Lmxla, and Nurr1) plus the gene for green fluorescent protein (gfp) to track transduction. These TF genes are involved in DA neuron differentiation, and have been shown to directly transdifferentiate fibroblasts into DA-like neurons14. An adenovirus serotype 5 was chosen over other viruses, due to the fact that, unlike lentiviruses and retroviruses, the adenovirus does not integrate with the genome of transduced cells. Furthermore, by utilizing a single adenoviral vector, this method allows for a homogenous transduction of the TF genes, and decreases variability within other protocols that utilize morphogens in addition to viral vectors.

\section{Methods}

\section{Gene cloning}

RNA for Complementary DNA (cDNA) synthesis was isolated from a brain hemisphere of a 1 day old rat pup. RNA was isolated and purified by using the RNeasy kit (Qiagen $\odot$ ). cDNA was synthesized from the RNA utilizing cDNA synthetase (Qiagen $\odot$ ). The amplified genes ( Table 1, for primer sequences) were then purified with a PCR product purification kit (Qiagen $\odot$ ), single gene products and the pGEM T-easy vector were ligated with T4 ligase (NEB), and JM109 competent cells were transformed with the ligated plasmid. Ampicillin-resistant colonies were purified using a miniprep plasmid purification kit (Qiagen $\odot$ ). The pGEM T-easy vector plasmids containing each TF, gfp, and $2 \mathrm{~A}$ genes for viral construction were verified by PCR, restriction endonuclease digestion, and DNA sequencing.

\section{Adenovirus production}

For virus production, the HEK 293 cell line was cultured until $90 \%$ confluent across the bottom of a $75 \mathrm{~cm}^{2}$ culture flask in growth media (Gibco ${ }^{\circ}$ DMEM, with $20 \%$ fetal bovine serum and $1 \%$ penicillin and streptomycin). Once $90 \%$ confluence had been obtained, $1.0 \times 106$ cells were replated in a $60 \mathrm{~mm}^{2}$ culture dish. The following day, the media was removed from the dish and replaced in growth media, without serum, and containing the transfection reagent, extreme gene HP (Promega), and the viral vector and viral backbone (Cell Biolabs). At 7 to 10 days, the cells were removed from the flask and the viral product was purified, than expanded.

\section{MSC transfection}

The MSCs were extracted from the rat bone marrow of the femur and tibia, following the method described by Rossignol and colleagues $[14,15]$. Following aspiration, the bone marrow was suspended in 10 $\mathrm{mL}$ of DMEM, 15\% fetal bovine serum (DMEM, Invitrogen; FBS, Invitrogen), and $1 \%$ penicillin/streptomycin. The MSCs were selected by plastic adherence. Following further verification by flow cytometry, the MSCs were cultured for 72 hours in neuronal induction medium, which consisted of DMEM/F12 Ham with 2\% fetal bovine serum, 1\% B27 serum and the adenovirus expressing the TFs. After 72 hours, the medium was changed. The transfection efficiency was measured by the expression of gfp. Cells were counted with a hemocytometer prior to transfection, and following transfection the cells were removed from the flask and recounted with a hemocytometer and a flow cytometer.

\section{Flow cytometry}

Cells were counted and evenly distributed into a 96 well plate. The cells were then washed twice with PBS, containing $1 \%$ bovine serum albumin (Invitrogen), and then centrifuged at $2,500 \mathrm{rpm}$ at $4^{\circ} \mathrm{C}$ for one minute. Following centrifugation, the supernatant was removed. After the two PBS washes, the cells were resuspended in the primary antibody (Table 2, for list of primary antibodies) and incubated overnight at $4^{\circ} \mathrm{C}$. The cells were then centrifuged at $2,500 \mathrm{rpm}$ at $4^{\circ} \mathrm{C}$ for one minute, and the supernatant was removed. Following removal of the supernatant,

\begin{tabular}{|l|l|c|}
\hline Gene & Primer sequence & 5' restriction site \\
\hline \multirow{2}{*}{ Ascl1 } & $\begin{array}{l}\text { F 5'-ATCGAT CTCGAGAGTGAGAGCTCTGGCAAGATGG-3' } \\
\text { R 5'-ACTAGTTGGGCCAGGATTCTCCTCGACGTCACCGCATGTTAGCAGA } \\
\text { CTTCCTCTGCCCTCTCCACTGCCGAACCAGTTGTTGGTAAAGTCCAGC-3' }\end{array}$ & Clal and Xhol \\
\hline Lmx1a & $\begin{array}{l}\text { F 5'-ACTAGTATGTTGGACGGCCTGAAGATGG-3' } \\
\text { R 5'-AAGCTTAGAGGTGAAATAGGAATTCTGCATGG-3' }\end{array}$ & Spel \\
\hline Nurr1 & $\begin{array}{l}\text { F 5'-ATCGATATGCCTTGTGTTCAGGCGCAG-3' } \\
\text { R 5'-AAGCTTGAAAGGTAAGGTGTCCAGGAAAAG-3' }\end{array}$ & Spel \\
\hline $2 A$ & $\begin{array}{l}\text { F 5'-AAGCTTGGCAGTGGAGAGGGCAGA-3' } \\
\text { R 5'-CTCGAGTGGGCAGGATCTCCTC-3' }\end{array}$ & Clal \\
\hline gfp & $\begin{array}{l}\text { F 5'-CTCGAGATGGTGAGCGTGAGCAAGGGCGAGGAG-3' HindIII } \\
\text { R 5'-GCGGCCGCTTACTTGTACAGCTCGTCCATG-3' }\end{array}$ & HindIII \\
\hline
\end{tabular}

Table 1: Primer sequences for cloning.

\begin{tabular}{|c|c|c|c|c|c|}
\hline Primary Anti-bodies & Isotype & Target & Concentration & dilution & company \\
\hline Mouse Anti-CD29 & $\lg G$ & CD29 & $1 \mathrm{mg} / \mathrm{mL}$ & $1: 500$ & Abcam \\
\hline Mouse Anti-CD44 & $\lg G$ & CD44 & $1 \mathrm{mg} / \mathrm{mL}$ & $1: 500$ & Abcam \\
\hline Mouse Anti-CD90 & $\lg G$ & CD90 & $1 \mathrm{mg} / \mathrm{mL}$ & $1: 500$ & Abcam \\
\hline Mouse Anti-SSEA4 & $\lg G$ & SSEA4 & $1 \mathrm{mg} / \mathrm{mL}$ & $1: 500$ & Abcam \\
\hline Mouse Anti-MHCII & $\lg G$ & MHCII & $1 \mathrm{mg} / \mathrm{mL}$ & $1: 500$ & Abcam \\
\hline Mouse Anti-CD105 & $\lg G$ & CD105 & $1 \mathrm{mg} / \mathrm{mL}$ & $1: 500$ & Abcam \\
\hline Rat Anti-SCA1-FITC & $\lg G$ & SCA1 & $1 \mathrm{mg} / \mathrm{mL}$ & $1: 500$ & Abcam \\
\hline Rabbit Anti-CD45 & $\lg G$ & CD45 & $1 \mathrm{mg} / \mathrm{mL}$ & $1: 500$ & Abcam \\
\hline Rabbit Anti-MHC I & $\lg G$ & MHC I & $1 \mathrm{mg} / \mathrm{mL}$ & $1: 500$ & Abcam \\
\hline
\end{tabular}

Table 2: Primary anti-bodies utilized to verify MSCs. 
Citation: Welchko RM, Hulse TD, Dieffenbach SS, Shall GP, Wangjing H, et al. (2018) Trans-Differentiation of Rat Mesenchymal Stem Cells into Dopaminergic Neurons for Cell Transplantation. J Stem Cell Res Ther 8: 421. doi: 10.4172/2157-7633.1000421

Page 3 of 7

the cells were then incubated in the secondary antibody for one hour (Table 3, for list of secondary antibodies). The cells were then washed three times, centrifuged after each wash, and placed in .1 M PBS with $4 \%$ paraformaldehyde. After 10 minutes, cells were washed once, resuspended in $300 \mu \mathrm{L}$ of PBS, and were stored at $4^{\circ} \mathrm{C}$ for flow cytometry analysis. Flow cytometry was conducted utilizing a BD LSR II flow cytometer (BD Biosciences) with forward scatter (FSC) and side scatter (SSC) emissions calibrated using BD calibration beads. The BD FACSdiva software was utilized to manage the flow cytometry system and data collection. Data was presented in a scatter plot as percentage of cells per wavelength emission of secondary antibody fluorophore.

\section{Immunocytochemistry}

Transduced cells were grown on coverslips, fixed with $4 \%$ paraformaldehyde in $0.1 \mathrm{M}$ PBS, followed by three washes in $0.1 \mathrm{M}$ PBS. The cells were then incubated in normal goat serum (Jackson ImunnoResearch Laboratories) to block non-specific antibody binding. Following incubation in the blocking serum, the cells were incubated with primary antibody (Table 4, for list of primary antibodies) overnight or 48 hours (for the TFs) at $4^{\circ} \mathrm{C}$. Following primary antibody incubation, the cells were washed in 0.1 M PBS, three times, and then incubated in the secondary antibody (Goat anti-Rb Alexa 594) for one hour at room temperature. The cells were then washed, three times in $0.1 \mathrm{M}$ PBS and mounted with Fluoromount ${ }^{\mathrm{Tw}}$ aqueous mounting media (Sigma-Aldrich).

\section{Western blot}

Cells were removed from media and homogenized within RIPA buffer. After extraction, protein samples were measured with BCA analysis and diluted to equal concentrations. The samples were placed in loading and were denatured by boiling at $100^{\circ} \mathrm{C}$ for five minutes. Protein was separated with a SDS-PAGE gel and transferred to a nitrocellulose membrane (Invitrogen). Following transfer the membrane was incubated in $5 \%$ non-fat milk overnight at $4^{\circ} \mathrm{C}$. The next day the membrane was incubated in the primary antibodies for the transduced TFs (ASCL1, LMX1a, and NURR1,) for 1 hour at room temperature. The membrane was washed in PBS three times, followed by incubation in the secondary antibody (Goat anti-Rb HRP conjugated) for 30 minutes. The secondary antibody was detected using PierceTM enhanced chemiluminescence solution (Thermofisher Scientific, St. Louis, MO), and developed with X-ray film.

\section{RT-PCR}

All of the culture media was removed from the culture dish and approximately 500,000 cells were subsequently washed three times in $10 \mathrm{~mL} 0.1 \mathrm{M}$ phosphate buffered saline (PBS). Following washing, TRIzol $^{\circ}$ (Invitrogen) reagent was added to the flask and the cells were incubated for five minutes to lyse the cells. RNA from the lysate was purified according to the protocol provided by the manufacture (Invitrogen). Complimentary DNA (cDNA) was then transcribed from the RNA utilizing the Quantitech Reverse Transcriptase kit (Qiagen) following the protocol provided by the manufacturer. The cDNA was subsequently utilized in a RT- PCR reaction to assess the relative mRNA expression levels of certain genes. The RT-PCR reactions were performed in replicates of three and repeated three times. RT-PCR reactions consisted of $1 \mu \mathrm{L}$ of cDNA, $1 \mu \mathrm{L}$ of the $20 \mu \mathrm{M}$ reverse and forward primers (Table 5 for sequences of primers), and $23 \mu \mathrm{L}$ RT-PCR SYBR green master mixes. The thermal cycler was set with a 10 minute long incubation at $95^{\circ} \mathrm{C}$ to activate the polymerase enzyme for the

\begin{tabular}{|c|c|c|c|c|}
\hline $\begin{array}{c}\text { Secondary Anti- } \\
\text { bodies }\end{array}$ & Target & Concentration & Dilution & Company \\
\hline $\begin{array}{c}\text { Anti-mouse-alexa } \\
488\end{array}$ & Mouse IgG & $2 \mathrm{mg} / \mathrm{mL}$ & $1: 500$ & Life Technologies \\
\hline Anti-rabbit-alexa 488 & Rabbit IgG & $2 \mathrm{mg} / \mathrm{mL}$ & $1: 500$ & Life Technologies \\
\hline
\end{tabular}

Table 3: Secondary anti-bodies utilized to label primary anti-bodies.

\begin{tabular}{|l|c|c|c|c|c|}
\hline $\begin{array}{l}\text { Primary Anti- } \\
\text { bodies }\end{array}$ & Isotype & Target & Concentration & dilution & company \\
\hline $\begin{array}{l}\text { Rabbit Anti- } \\
\text { LMX1a }\end{array}$ & $\operatorname{lgG}$ & TH & $1 \mathrm{mg} / \mathrm{mL}$ & $1: 500$ & Abcam \\
\hline $\begin{array}{l}\text { Rabbit Anti- } \\
\text { NURR1 }\end{array}$ & $\operatorname{lgG}$ & $\mathrm{CD} 44$ & $1 \mathrm{mg} / \mathrm{mL}$ & $1: 500$ & Abcam \\
\hline Rabbit Anti-TH & IgG & CD90 & $1 \mathrm{mg} / \mathrm{mL}$ & $1: 500$ & Abcam \\
\hline Rabbit Anti-DAT & $\operatorname{lgG}$ & $\mathrm{SSEA4}$ & $1 \mathrm{mg} / \mathrm{mL}$ & $1: 500$ & Abcam \\
\hline $\begin{array}{l}\text { Rabbit Anti- } \\
\text { GIRK2 }\end{array}$ & $\operatorname{lgG}$ & MHCII & $1 \mathrm{mg} / \mathrm{mL}$ & $1: 500$ & Abcam \\
\hline $\begin{array}{l}\text { Mouse Anti- } \\
\text { ASCL1 }\end{array}$ & $\operatorname{lgG}$ & $\mathrm{CD} 105$ & $1 \mathrm{mg} / \mathrm{mL}$ & $1: 500$ & Abcam \\
\hline
\end{tabular}

Table 4: Primary anti-bodies utilized to verify DA-like Cells.

\begin{tabular}{|c|c|}
\hline Gene & Primer sequence \\
\hline \multirow{2}{*}{ Ascl1 } & F 5'-CCTACGACCCCCTTAGTCCA-3' \\
& R 5'-TGCCATCCTGCTTCCAAAGT-3' \\
\hline \multirow{2}{*}{ Lmx1a } & F 5'-TCTCTGCACAGCCCACATAG-3' \\
& R 5'-TCCATCTACCATGCCTCTCC-3' \\
\hline \multirow{2}{*}{ Nurr1 } & F 5'-GGTTCATGTCTCCCTTCTGTAG-3' \\
\hline \multirow{2}{*}{ FoxA2 } & R 5'-GAGCCAAAATGCCCTTTCAC-3' \\
\hline \multirow{2}{*}{ Pitx3 } & F 5'-GTGGGTAGCCAGAAAAGGC-3' \\
& R 5'-CAGCATACTTTAACTCGCTGGC-3' \\
\hline \multirow{2}{*}{ Msx1 } & F 5'-CATGGAGTTTGGGCTGCTTG-3' \\
& R 5'-CCTTCTCCGAGTCACTGTGC-3' \\
\hline \multirow{2}{*}{ TH } & F 5'-TGCTAAGGCCAAGAGACTGC-3' \\
& R 5'-CAAGAGGAAAGGAGAGGCCG-3' \\
\hline \multirow{2}{*}{ Dat } & F 5'-TGTGTCCGAGAGCTTCAATG-3' \\
& R 5'-GGGCTGTCCAGTACGTCAAT-3' \\
\hline F 5'-GCTCCAGGAAGGGTAACTCC-3' \\
R 5'-GCTCCAGGAAGGGTAACTCC-3'
\end{tabular}

Table 5: RT-Primer sequences.

first step. The second step consisted of a 15 second incubation period at $95^{\circ} \mathrm{C}$, followed by 1 minute incubation at $60^{\circ} \mathrm{C}$ and this process was repeated for a total of 40 cycles. Results were analyzed utilizing the $2^{-\Delta \Delta C T}$ method. The Student's t-test was used to compare the mean mRNA expression of each gene within the transfected and control MSCs at individual time points ( 3 and 5 days).

\section{HPLC}

To quantify DA levels in reprogrammed cells, cell pellets were homogenized in $100 \mu \mathrm{l} 0.1 \mathrm{~N} \mathrm{HClO} 4$ and analyzed by using HPLC with electrochemical detection (ESA). To measure dopamine concentrations in the supernatants, cells were exposed to DMEM media for $30 \mathrm{~min}$ followed by DMEM media with $50 \mathrm{mM} \mathrm{KCl}$ for $30 \mathrm{~min}$, then $0.9 \mathrm{ml}$ of supernatants were collected with the addition of $0.1 \mathrm{ml}$ of $1 \mathrm{~N} \mathrm{HClO} 4$, and analyzed by HPLC. Dopamine was separated on a reverse-phase column (Capcell PAK, $3 \mu \mathrm{m}, 50 \times 1 \mathrm{~mm}$ ) with a mobile phase consisting of $150 \mathrm{mM}$ phosphate buffer, $4.76 \mathrm{mM}$ citric acid, 3mM SDS, $0.05 \mathrm{mM}$ EDTA, $10 \%$ methanol, $15 \%$ acetonitrile ( $\mathrm{pH} 6.0$ ) at a flow rate of $200 \mu \mathrm{L}$ min. Dopamine was detected by a Decade II electrochemical detector 

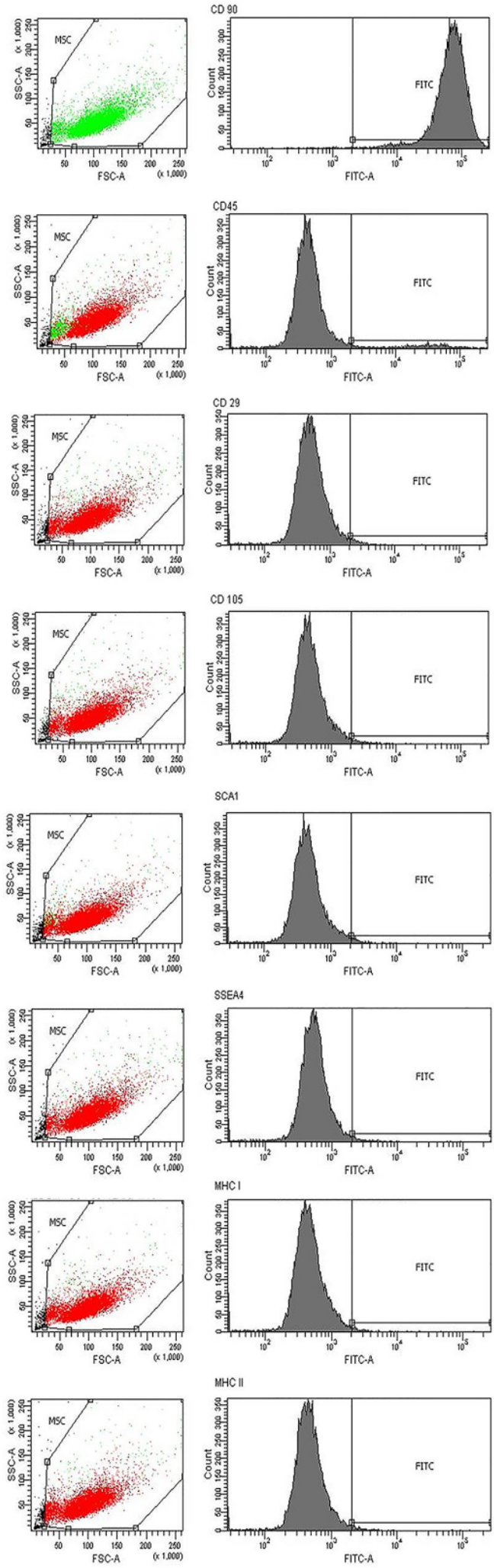

Figure 1: MSC Cell Scatter Plot Graph. Graphs represent the MSC cell population based on non-MSC markers, and MSC marker CD90. Cells were only positive for CD90.
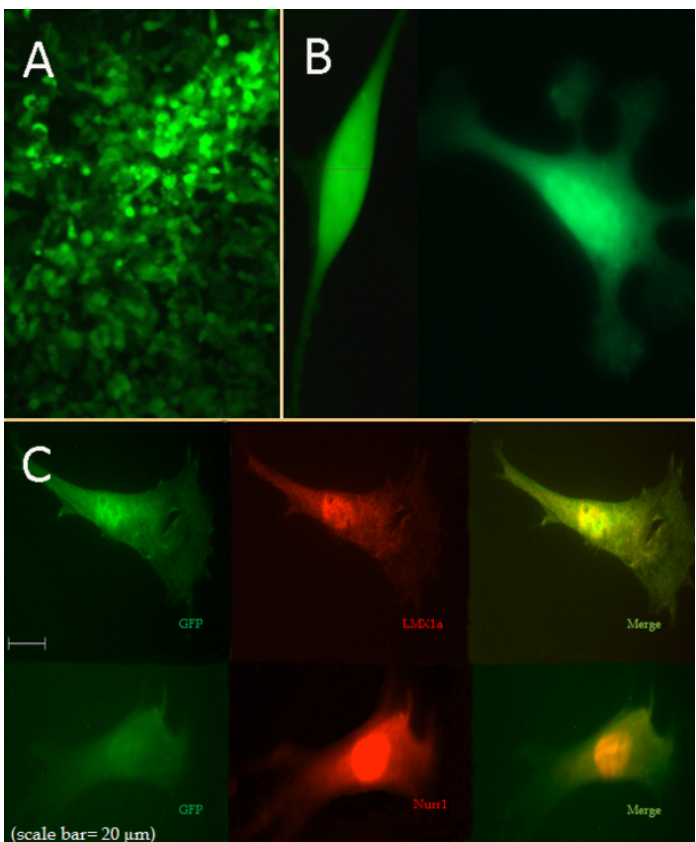

Figure 2: A. plaque formation seen after 10 days post-transfection indicating viral production B. Cellular Morphology; A representation of the typical morphological change seen in transduced MSCs at days three and five respectively. C. LMX1a and Nurr1 Fluorescent Images: these images illustrate the presence of LMX1a and NURR1 within the nucleus of transfected MSCs. Scale bar=20 $\mu \mathrm{L}$

equipped with a electrochemical flow cell and a 0.7 -mm-diameter glassy carbon electrode (ESA). The volume of the injection was $20 \mu \mathrm{L}$. Results were compared to known DA standards.

\section{Results}

Flow cytometry was performed on the MSC population to verify stem cell lineage through the use of immunocytochemistry labeling of extracellular non-MSC cell and MSC markers. The MSCs were negative for extracellular, non-stem cell markers while $99.7 \%$ of the MSCs were positive for the extracellular stem cell marker CD90 (Figure 1).

Following the cloning process for the genes 2A, Ascl1, gfp, Lmxla, and Nurr1, production of each plasmid was confirmed with PCR and restriction endonuclease digestion. All of the plasmids were positive for the genes cloned, which were verified by the expected product size. Following confirmation with PCR amplification and restriction digest, plasmids were sequenced from the 5' to the 3 ' end using the T7 primer and sequenced from the 3' to 5' end using the SP6 primer. The construct plasmids were also confirmed and verified in the same manner. Upon completion of viral production, each of the cloned genes, Ascl1, gfp, Lmxla, and Nurrl were verified to be present in the viral genome by PCR.

Viral production was confirmed by the formation of a plaque in a culture of HEK 293 cells (Figure 2A) Following transduction of the MSCs, the viral titer $3.195 \times 1093.195 \times 109$ infectious units/ $\mathrm{mL}$ was determined to be the most efficient based upon the level of gfp expression, with a transduction efficiency of $90.35 \%$, verified by two methods (utilizing a hemocytometer and flow cytometer). The transduced cells displayed a change in morphology in which the cells became elongated after 3 days post transfection (Figure 2B). Immunocytochemistry results demonstrated nuclear localization of the 
A
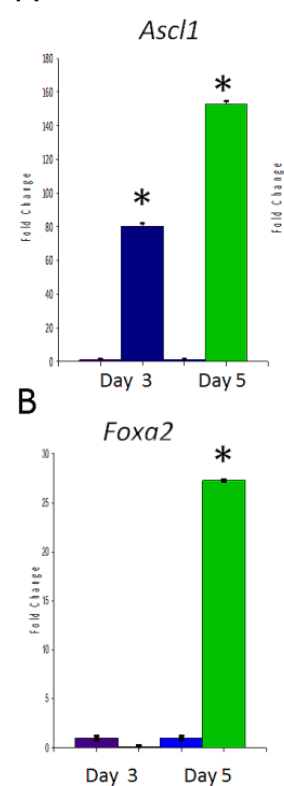

C

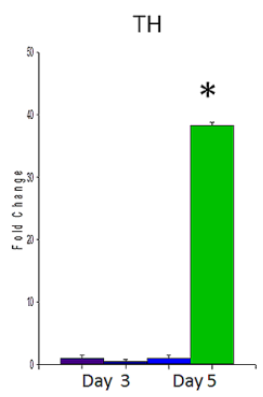

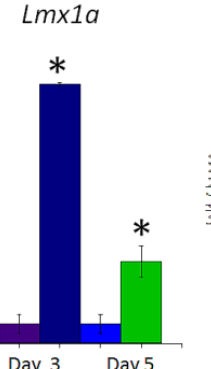
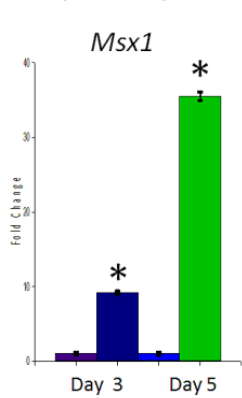

D
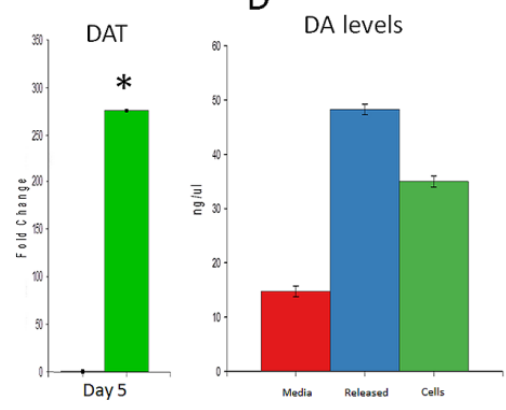

Figure 3: A-C. RT-PCR Results; graphs demonstrating the fold changes in mRNA levels of genes in transfected cells compared to time matched contro MSCs $(p<0.05)$. D. DA content was measured within the media prior to $\mathrm{KCl}$ generated release, DA was measured after release, and the total amount of DA was measured within the cells.

transcription factors NURR1, and LMX1a at 7 days post-transfection (Figure 2C). These the results suggest that the observed morphological changes could be taking place via activated transcription factors. Additionally Western blot analysis at day three demonstrated that the protein expression was observed for all transduced genes (Ascl1, Lmxla, Nurr1, gfp; data not shown).

Utilizing RT-PCR, cells were monitored for gene up-regulation and down-regulation at post-transfection days 3 and 5, and analyzed with the $2^{-\Delta \Delta C T}$ method. Mean fold changes were compared to un-transfected MSCs with Student's t-test. The three transduced TFs (Ascl1, Lmxla, and Nurr1) within the adenovirus were found to be significantly upregulated at both time points, as expected. Ascl1 day $3(\mathrm{t}(1)=46.797, \mathrm{p}<0.01)$, day $5(\mathrm{t}(1)=11558.667, \mathrm{p}<0.0001)$; Lmxla day $3(\mathrm{t}(1)=13.342, \mathrm{p}<0.05)$, day $5(\mathrm{t}(1)=351.005, \mathrm{p}<0.002)$; Nurrl day $3(\mathrm{t}(1)=173.125, \mathrm{p}<0.004)$, day $5(\mathrm{t}(1)=555.063, \mathrm{p}<0.001)$ (Figure $3 \mathrm{~A})$. The mRNA of the direct and indirect gene targets of these TFs were found to be upregulated as well, suggesting active transcription. These TFs included Msx1, FoxA2, and Pitx. Msx1 day 3 (t $(1)=347.616, \mathrm{p}<0.002)$, day 5 (t (1) $=963.530, \mathrm{p}<0.001)$; FoxA2 day 5 (t $(1)=801, \mathrm{p}<0.001)$; Pitx3 day $5(\mathrm{t}(1)=73.86, \mathrm{p}<0.0001)$ (Figure 3B). Furthermore mRNA levels for $\mathrm{TH}$ and the DAT were found to be upregulated, TH days $5(\mathrm{t}$ $(1)=1884.872, \mathrm{p}<0.0001)$, DAT day $5(\mathrm{t}(1)=770.231, \mathrm{p}<0.001)$ (Figure 3C).

Following these results, the induced MSCs into DA like-cells were characterized for DA production utilizing HPLC. The cells were found to spontaneously release DA, release dopamine upon stimulation with high $(50 \mathrm{mM}) \mathrm{K}+$ stimulation, and contain DA after release (Figure 3D).

\section{Discussion}

The successful cloning of each TF (Ascl1, Lmxla, and Nurr1), in addition to the other genes included in the virus (2A, gfp), was confirmed by PCR, restriction digest, and nucleotide sequencing. Important concerns that arise with polycistronic expression of numerous genes are: (1) whether the genes will be expressed as a single protein or separate proteins; and (2) if and how protein folding will be affected, based on the function of the $2 \mathrm{~A}$ peptide. The way in which the $2 \mathrm{~A}$ peptide cleaves is upon translation of codon, which is located towards the 3' end of the mRNA, which causes translation to stop and start. This action leaves 20 amino acids on the 3 ' end of the translated gene upstream from the $2 \mathrm{~A}$ sequence and 2 amino acids on the downstream-translated gene [16-20]. The functionality of the selfcleaving peptide $2 \mathrm{~A}$ is evident in this work, based upon a few factors. First, GFP was expressed in the transduced MSCs. The expression of GFP would not be observed if the 2A peptide had not cleaved, or had the addition of amino acids by the $2 \mathrm{~A}$ peptide caused the GFP protein to misfold. It can be argued that the innocuous functionality of the other 2A peptides included in the virus can be indirectly demonstrated by the RT-PCR results that were observed: Lmxla is significantly up regulated at days 3 and 5, along with the TF, Msx1. This demonstrates that LMX1a is functional, since the mRNA levels of the LMX1a target Msx1 are increased [21]. Additionally we observe upregulation of Nurr1 and, two important downstream targets of NURR1 (TH, DAT) were upregulated, corresponding with the trend in Nurr1 up-regulation [22-24]. Furthermore, at day 5 the transfected MSCs expressed the protein DAT. Therefore, based upon protein and mRNA expression, the functionality of the $2 \mathrm{~A}$ peptides can be directly and indirectly observed, demonstrating the translation of four genes into functional proteins from a single open reading frame, hereby illustrating a novel method of adenoviral mediated transduction.

For this novel method of adenoviral mediated transduction to bring about the trans-differentiation of MSCs in an efficient manner, the MSCs phenotype was partially verified, utilizing flow cytometry prior to examining the transduction efficiency. These two factors are important to discuss together since the transduction of MSCs and partially differentiated MSCs, known as mesenchymal progenitor cells (MPC), differ due the expression of the coxsackievirus and adenovirus receptor (CAR) [25]. CAR, which is the principle route for adenovirus transduction, is expressed at a high level on MSCs while the expression of CAR is expressed at a low level on MPCs $[25,26]$. Transduction efficiencies of $90.35 \%$ were observed in the MSCs within this study, which are not routinely observed in transduction of cell types that express low levels of CAR, such as MPCs. Further this level of transduction efficiency has been observed in human MSCs, which can also be directly impacted by the blockade of CAR [26]. The flow cytometry assay utilized antibodies accepted as a general marker screening panel. Our population sample of MSCs was $99.7 \%$ positive for the protein CD90, which is noteworthy, since it demonstrates a 
homogeneous population of cells expressing an accepted MSC marker [27]. These factors shown by transduction efficiency and flow cytometry, together, indicate that the cell type that we successfully modified in our study was more likely MSCs rather than the semi-differentiated MPCs.

MSCs have been shown to express TH and NURR1, suggesting that some expression of NURR1, and downstream targets of the NURR1, should be observed without transduction [28,29]. Despite this expression we still would expect to see significant upregulation in these genes evidenced by RT-PCR. As previously mentioned, Nurr1 was indeed significantly upregulated in differentiated cells compared to undifferentiated control MSCs. We also observed NURR1 labeling with Western blot and within the nucleus of transduced cells that coexpressed GFP. Based on the results of NURR1 expression, we would expect to see up-regulation of the down-stream targets of the TF, such as TH. TH is a target of the NURR1 TF within the rat species rattus norvegicus, and functions by binding to promoter region of the $\mathrm{TH}$ gene and eliciting transcription $[22,23]$. We also observed a significant fold increase (upregulation) in $\mathrm{TH}$, along with up-regulation of additional TFs that target TH indirectly and directly (such as FoxA2, and Pitx3) [30-32], which is indicative of active NURR1, and possible DA neuron-like cellular phenotype. Similar results were also observed by Tondreau and colleagues, upon neuronal induction [28]. Therefore taken together the RT-PCR results and ICC immunocytochemistry results thus far indicate a potential DA neuron-like cellular phenotype.

The argument that the cells in this study are terminally differentiating toward a DA neuron-like cellular phenotype is further supported by the mRNA expression of FoxA2 and Pitx3, which were significantly up-regulated at day 5 , compared to controls. FOXA2 has been found to be necessary for the survival of DA neurons, most likely through transcription activation of Pitx 3 and Nurr $1[33,34]$. None of the transcription factors that were transduced (Ascl1, Lmxla, and Nurr1) directly up-regulate FoxA2. However $\mathrm{SHH}$, which up-regulates FoxA2, has been shown to be indirectly upregulated by ASCL1 [35-37]. Further Pitx 3 has been found to be up-regulated by GDNF, which in turn upregulates BDNF [38]. Trzaska and colleagues (2009), as well as Peng and colleagues (2011), have shown that BDNF increases DA neuronal cell survival and in fact helps to finalize neuronal status promoting expected calcium-dependent release from neurons [12,38]. In fact, Trzaska and colleagues have shown that BDNF increases the amplitude of action potentials expressed by DA neurons that were derived from MSCs, along with the more neuronal $\mathrm{Ca}^{+-}$dependent) status of release, illustrating that the expression of NURR1, FOXA2, and PITX3, alone will not bring about mature DA neurons through differentiation or trans-differentiation in the absence of BDNF.

The HPLC analysis of dopamine release indirectly demonstrates the TFs LMX1a, FOXA2, NURR1, and PITX3 are functional TF, since the cells released dopamine and exhibited some residual dopamine within the cells (Figure 3D). Potassium-stimulated release suggests mechanisms are in place that supports action potential-derived exocytosis rather than a simple reversal of transport or leakage, which would not be calcium dependent, which is normally observed in the dorsal striatum [39]. In fact, early experiments by Trzaska and colleagues, before the addition of BDNF in their protocol, yielded cells that lacked sufficient electrical activity and did not yield $\mathrm{K}+$-stimulated release [40]. As was shown in Figure 3C, our cell populations were expressing considerable $\mathrm{TH}$ and DAT and their demonstrated sensitivities to $\mathrm{K}+$ stimulation indicate that the mechanisms of action potential generation were in place. The presence of DA prior to stimulation suggests that certain levels of spontaneous oscillations may be occurring among these cells, though the osmotic conditions of our assay may deviate somewhat from standard in-vivo conditions. It will be important to explore how these cells responded to the typical context in the dorsal striatum, where glutamatergic and GABA-ergic stimulations are routine. Further we confirmed expression and of the G-protein regulated inward rectifier potassium channel 2 (GIRK2; data not shown) which has been shown to be crucial for A9 DA neuronal oscillatory function [41,42]. Moreover, the expression of GIRK2 is utilized as a marker for this phenotype, with this phenotype shown to provide the greatest amount of integration and survival when transplanted within the striatum [41].

Further, in vitro and in vivo experimentation with this method of viral induction of DA-like cells need to be undertaken. First, the presence of additional proteins involved in the A9 and A10 DA cell function need to be both shown and excluded, such as calbindin and aldh1a [43]. This distinction is crucial since A10 DA neurons or ventral tegmentum area DA neurons have been shown to not integrate within the striatum as efficiently [43]. The in vivo transplantation of these cells is needed to demonstrate cell survivability and integration within the host tissue. Nonetheless, our current in vitro findings suggest that the trans-differentiation of MSCs into DA like cells is not only possible, but may provide a new means of facilitating cell replacement therapy.

\section{Conclusion}

In conclusion, the results of this study suggest the transfected MSCs have a DA-cell-like phenotype, based upon morphology, mRNA, and protein expression. The cellular morphology of some transduced cells within this study demonstrated a circular shaped body with finger-like projections extending from this body, which is similar to immature DA neurons (Figure 2B). Based upon the RT-PCR results the mRNA expression profile resembled that of a DA like cell, and immunohistochemical verification of protein expression (i.e. $\mathrm{TH}$, DAT) confirms said genes are translated, while DA release suggests that they are functional. Furthermore, this body of work demonstrates that a single adenovirus can bring about the poly-cistronic expression of multiple genes with transfection efficiencies as high as $90 \%$, evidenced by the expression of GFP. This is of particular importance in obtaining a purer population of cells that can be utilized for cellular transplantation in PD.

Our research suggests a strategy that provides the potential of two beneficial attributes. First, our strategy seems to drive greater levels of DA phenotype induction compared with similar cells left to their own devices or vulnerable to only local morphogen cues. Secondly, this strategy could theoretically be applied to mesenchymal populations obtained from the patients themselves, avoiding immune rejection and presumably prolonging their effectiveness. Therefore, if side effects such as GIDs do in fact derive from alternative cell type contributions, our strategy may show a comparative reduction in such expressions. Future studies involving transplanting such cells into the dorsal striatum of animals after dopamine-depleting lesions will allow focused explorations with in-vivo behavioral testing, confirming their viability under both spontaneous and stimulated conditions.

\section{References}

1. Kowal S, Dall T, Chakrabarti R, Storm M, Jain A (2013) The Current and Projected Economic Burden of Parkinson's Disease in the United States. Mov Dis 28: 311-318. [PubMed]

2. Alexander GE (2004) Biology of Parkinson's disease: Pathogenesis and pathophysiology of a multisystem neurodegenerative disorder. Dialog Clin Neurosci 6: 259-280. [PubMed] 
Citation: Welchko RM, Hulse TD, Dieffenbach SS, Shall GP, Wangjing H, et al. (2018) Trans-Differentiation of Rat Mesenchymal Stem Cells into Dopaminergic Neurons for Cell Transplantation. J Stem Cell Res Ther 8: 421. doi: 10.4172/2157-7633.1000421

3. Hely MA, Morris JG, Reid WG, O'Sullivan DJ, Williamson PM, et al. (1994) The Sydney Multicentre Study of Parkinson's disease: a randomised, prospective five year study comparing low dose bromocriptine with low dose levodopacarbidopa. J Neurol, Neurosurg, Psych 57: 903-910. [PubMed]

4. Freed CR, Zhou W, Breeze RE (2011) Dopamine cell transplantation for Parkinson's disease: the importance of controlled clinical trials. Neurotherapeutics: J American Society Exp NeuroTherap 8: 549-561. [PubMed]

5. Wenning GK, Odin P, Morrish P, Rehncrona S, Widner H, et al. (1997) Shortand long-term survival and function of unilateral intrastriatal dopaminergic grafts in Parkinson's disease. Arch Neurol 42: 95-107. [PubMed]

6. Hauser R, Freeman T, Snow B, Nauert M, Gauger L, et al. (1999) Long-term evaluation of bilateral fetal nigral transplantation in Parkinson's disease. Arch Neurol 56: 179-187. [PubMed]

7. Hagell P, Schrag A, Piccini P, Jahanshahi M, Brown R, et al. (1999) Sequential bilateral transplantation in Parkinson's disease: Effects of the second graft. Brain 122: 1121-1132. [PubMed]

8. Brundin, P., Pogarell, O., Hagell, P., Piccini, P., Widner, H., et al. (2000) Bilateral caudate and putamen grafts of embryonic mesencephalic tissue treated with lazaroids in Parkinson's disease. Brain, 123: 1380-1390. [PubMed]

9. Freed CR, Greene PE, Breeze RE, Tsai WY, DuMouchel W (2001) Transplantation of embryonic dopamine neurons for severe Parkinson's disease. New Eng J Med 344: 710-719. [PubMed]

10. Olanow C, Goetz C, Kordower J, StoessI A, Sossi V, et al. (2003) A double-blind controlled trial of bilateral fetal nigral transplantation in Parkinson's disease. Ann Neuro 54: 403-414. [PubMed]

11. Politis M, Oertel W, Wu K, Quinn N, Pogarell O, et al. (2011) Graft-induced dyskinesias in Parkinson's disease: High striatal serotonin/dopamine transporter ratio. Mov Dis 26: 1997-2003. [PubMed]

12. Trzaska KA, King CC, Li KY, Kuzhikandathil EV, Nowycky MC, et al. (2009) Brain-derived neurotrophic factor facilitates maturation of mesenchymal stem cell-derived dopamine progenitors to functional neurons. J Neurochem 110: 1058-1069. [PubMed]

13. Barzilay R, Ben-Zur T, Bulvik S, Melamed E, Offen D (2009) Lentiviral delivery of $L m \times 1 a$ enhances dopaminergic phenotype in differentiated human bone marrow mesenchymal stem cells. Stem cells and development 18: 591-601. [PubMed]

14. Caiazzo M, Dell'Anno MT, Dvoretskova E, Lazarevic D, Taverna S, et al. (2011) Direct generation of functional dopaminergic neurons from mouse and human fibroblasts. Nature 476: 224-227. [PubMed]

15. Rossignol J, Fink K, Davis K, Clerc S, Crane A, et al. (2014) Transplants of adult mesenchymal and neural stem cells provide neuroprotection and behavioral sparing in a transgenic rat model of Huntington's disease. Stem Cells 32: $500-$ 509. [PubMed]

16. Szymczak AL, Workman CJ, Wang Y, Vignali KM, Dilioglou S, et al. (2004) Correction of multi-gene deficiency in vivo uses a single "self-cleaving" $2 \mathrm{~A}$ peptide-based retroviral vector. Nature Biotech 22: 589-594. [PubMed]

17. Provost E, Rhee J, Leach SD (2007) Viral 2A peptides allow expression of multiple proteins from a single ORF in transgenic zebra fish embryos. Genesis 45: 625-629. [PubMed]

18. Trichas G, Begbie J, Srinivas S (2008) Use of the viral 2A peptide for bicistronic expression in transgenic mice. BMC Biology 6: 40. [PubMed]

19. Szymczak-Workman AL, Vignali KM, Vignali DAA (2012) Design and construction of $2 \mathrm{~A}$ peptide-linked multicistronic vectors. Cold Spring Harbor Protocols 2012: 199-204. [PubMed]

20. Szymczak-Workman AL, Vignali KM, Vignali DAA (2012) Verification of 2A peptide cleavage. Cold Spring Harbor Protocols 255-257. [PubMed]

21. Andersson E, Tryggvason U, Deng Q, Friling S, Alekseenko Z, et al. (2006) Identification of Intrinsic Determinants of Midbrain Dopamine Neurons. Cell 124: 393-405. [PubMed]

22. Sakurada K, Ohshima-Sakurada M, Palmer TD, Gage FH (1999) Nurr1, an orphan nuclear receptor, is a transcriptional activator of endogenous tyrosine hydroxylase in neural progenitor cells derived from the adult brain. Development (Cambridge, England) 126: 4017-4026. [PubMed]

23. Wang M, Banerjee K, Baker H, Cave JW (2015) Nucleotide sequence conservation of novel and established cis-regulatory sites within the tyrosine hydroxylase gene promoter. Front in Bio 10: 74-90. [PubMed]
24. Volpicelli F, De Gregorio R, Pulcrano S, Perrone-Capano C, di Porzio U, et al. (2012) Direct regulation of Pitx3 expression by Nurr1 in culture and in developing mouse midbrain. Plos One 7: e30661. [PubMed]

25. Kawabata K, Sakurai F, Koizumi N, Hayakawa T, Mizuguchi H (2006) Adenovirus vector-mediated gene transfer into stem cells. Mol Pharma 3: 95103. [PubMed]

26. Conget PA, Minguell JJ (2000) Adenoviral-mediated gene transfer into ex vivo expanded human bone marrow mesenchymal progenitor cells. Exp Hemat 28 : 382-390. [PubMed]

27. Rossignol J, Boyer C, Thinard R, Remy S, Dugast AS, et al. (2009) Mesenchymal stem cells induce a weak immune response in the rat striatum after allo or xenotransplantation. J Cel Mol Med 13: 2547-2558. [PubMed]

28. Tondreau T, Lagneaux L, Dejeneffe M, Massy M, Mortier C, et al. (2004). Bone marrow-derived mesenchymal stem cells already express specific neural proteins before any differentiation. Diff Res Bio Divers 72: 319-326. [PubMed]

29. Moradi F, Haji Ghasem Kashani M, Ghorbanian MT, Lashkarbolouki T (2012) Spontaneous Expression of Neurotrophic Factors and TH, Nurr1, Nestin Genes in Long-term Culture of Bone Marrow Mesenchymal Stem Cells. Cell 13: 243250. [PubMed]

30. Ferri ALM, Lin W, Mavromatakis YE, Wang JC, Sasaki $\mathrm{H}$, et al. (2007) Foxa1 and Foxa2 regulate multiple phases of midbrain dopaminergic neuron development in a dosage-dependent manner. Development (Cambridge, England) 134: 2761-2769. [PubMed]

31. Yi SH, He XB, Rhee YH, Park CH, Takizawa T, Nakashima K, et al. (2014) Foxa2 acts as a co-activator potentiating expression of the Nurr1-induced DA phenotype via epigenetic regulation. Stem Cells and Development 23: 477487. [PubMed]

32. Hong S, Chung S, Leung K, Hwang I, Moon J, et al. (2014). Functional roles of Nurr1, Pitx3, and Lmx1a in neurogenesis and phenotype specification of dopamine neurons during in vitro differentiation of embryonic stem cells. Stem Cell Develop 23: 477-487.

33. Stott SRW, Metzakopian E, Lin W, Kaestner KH, Hen R, et al. (2013) Foxa1 and foxa2 are required for the maintenance of dopaminergic properties in ventral midbrain neurons at late embryonic stages. J Neurosci , 33: 8022-8034. [PubMed]

34. Kittappa R, Chang WW, Awatramani RB, McKay RD (2007) The foxa2 gene controls the birth and spontaneous degeneration of dopamine neurons in old age. PLoS Bio 5: e32. [PubMed]

35. Lin YT, Ding JY, Li MY, Yeh TS, Wang TW, et al. (2012) YAP regulates neurona differentiation through Sonic hedgehog signaling pathway. Peri Cell Res 318 : 1877-1888. [PubMed]

36. Zhang H, Deo M, Thompson RC, Uhler MD, Turner DL (2012) Negative regulation of Yap during neuronal differentiation. Develop Bio 361: 103-115. [PubMed]

37. Chung S, Leung A, Han BS, Chang MY, Moon JI, Kim et al. (2009) Wnt1 Imx1a forms a novel autoregulatory loop and controls midbrain dopaminergic differentiation synergistically with the SHH-FoxA2 pathway. Cell Stem Cell 5 : 646-658. [PubMed]

38. Peng C, Aron L, Klein R, Li M, Wurst W, et al. (2011) Pitx3 is a critical mediator of GDNF-induced BDNF expression in nigrostriatal dopaminergic neurons. J Neurosci 31: 12802-12815. [PubMed]

39. Wightman RM, Bright CE, Caviness JN (1981) Direct measurement of the effect of potassium, calcium, veratridine, and amphetamine on the rate of release of dopamine from superfused brain tissue. Life Sci 28: 1279-1286. [PubMed]

40. Trzaska KA, Kuzhikandathil EV, Rameshwar P (2007) Specification of a dopaminergic phenotype from adult human mesenchymal stem cells. Stem Cells 25: 2797-2808. [PubMed]

41. Lacey MG, Mercuri NB, North RA (1987) Dopamine acts on D2 receptors to increase potassium conductance in neurones of the rat substantia nigra zona compacta. J Physiol 392: 397-416. [PubMed]

42. Morikawa H,Paladini CA (2011) Dynamic regulation of midbrain dopamine neuron activity: intrinsic, synaptic, and plasticity mechanisms. Neurosci 198 95-111. [PubMed]

43. Thompson L, Barraud P, Andersson E, Kirik D, Björklund A (2005) Identification of dopaminergic neurons of nigral and ventral tegmental area subtypes in grafts of fetal ventral mesencephalon based on cell morphology, protein expression, and efferent projections. J Neurosci 25: 6467-6477. [PubMed] 